\title{
sciendo
}

\section{DIVERSITY AND THE DIFFICULTY OF LIVING IT: THE CASE OF PUBLIC SPACES IN SKOPJE (NORTH MACEDONIA)}

\author{
Katerina Mojanchevska \\ Independent social science researcher, graduate from the Institute of Social Studies, Erasmus \\ University Rotterdam, The Netherlands
}

katerina.mojanchevska@gmail.com

\begin{abstract}
Ethnic diversity and cultural heterogeneity are a reality for the city of Skopje, the capital of North Macedonia. The changing ethnic demography and redressed power-balance between majority and non-majority groups on local level have spurred a turbulent conflict - that of governance of diversity in public space. This paper aims to understand citizens' views on how language, ethnicity, religion and collective cultural symbols are legitimised through the political, social and symbolic value of public spaces in their neighbourhoods. The results indicate that the political value of public spaces to stimulate contact, deliberation and debate among citizens on issues of their concern is undermined. Public spaces in Skopje are not planned and managed through a wide forum of citizen engagement. The colliding ethnonationalism and symbolic power struggle between the major ethnic groups result in coethnic preferences in socialisation and selection of public spaces. The concept of "the appropriate citizen" constructed through the symbolic meaning of public spaces perpetuates ethnonational rhetoric and supports expressions of citizenship that are limited to the nationstate and ethnic identification. In opposition to contact theory, this research indicates that selfsegregation of ethnic groups can be prevalent in multi-ethnic neighbourhoods. This should make us think of the context where the contact is established and not only of the content of the interaction.
\end{abstract}

Keywords: Diversity, social interaction, public space, urban planning, Skopje. 


\section{INTRODUCTION}

The impact of diversity on neighbourhood cohesion has received a lot of research attention. The results, however, are inconclusive of unanimous positive or negative effect on urban life. Allport (1979) argues that contact among groups under certain conditions is an effective way to reduce anxiety, hostility, and prejudice. Working in activities which share common goals, promote cooperation and have the support of authorities enhance the likelihood of a positive outcome of the intergroup contact (Hewstone, 2003; Hewstone and Greenland, 2000; Pettigrew, 1998). On the other side, studies argued that too much diversity is detrimental to social integration (Putnam, 2007). Diversity affects interpersonal/intergroup relations as people tend to rely on those that are perceived as similar to themselves and with whom they share frequent contact. When encountered with diversity, people act with distrust and their capacity for intergroup cooperation and support for joint activities declines (Messick and Kramer, 2001). In fragmented societies, the effect of ethnic heterogeneity of the neighbourhood can trigger residents towards co-ethnic socialisation and identification. Changed power hierarchies between ethnic groups transform the relations and the social dynamic in the local setting. This brings us to the forefront of not only the influence of place-specific factors but also of cultural differences and ethnic identification in understanding the social outcomes of space production. The production of space as a political process may play a more important role in understanding integration and multiculturalism than the literature has acknowledged.

This research aims to answer how citizens conceptualise and make sense of practices through which diversity is accommodated in public spaces, how they make sense of places and construct multicultural encounters in public spaces. Despite the significant groundwork on the philosophical and pragmatic aspects of multiculturalism, there is relatively little knowledge of the public's understanding of multiculturalism and the public's views on fair and just accommodation of diversity. Since citizens are those who directly experiencing diversity, this remains an important question.

The study uses data acquired through household survey and in-depth interviews in four neighbourhoods in Skopje (two ethnically more homogenous and two ethnically mixed neighbourhoods) during 2014, the concluding year of the megalomanic urban and political project Skopje 2014.

It adds to the existing literature by examining the context where contact between groups is established and sustained. In particular, it adds to the potential of spaces to shape positive or 
negative outcomes when the formal equal status between ethnic groups could be challenged by social and economic inequality that at times collide with ethnic belonging. Moreover, this paper adds to the knowledge of governance of diversity in the cities by rethinking the planning practices of public spaces under diversity.

\section{THEORETICAL POSITIONING}

Space is increasingly described as a "combination of people, objects, and events" (Madanipour, 1996: 3). Dixon and Durrheim (2000: 27) note that: "who we are is often related to where we are". That is, our identity among other components is also triggered by places and environment with meaning to us, used for recreational, leisure or other purposes and by the social relations we develop in these spaces. And in this world of multiple identities, groups allegiance or location have become an important agency of subjectivity and personal identity (Duyvendak, 2004). Second, public space is more than a simple manifestation of personal identity. It spatialises symbols and metaphors referencing the collective memories of a group in such a way that it becomes a representation of the self-concept of the group. Third, changes in the wider political and social context raised by minority claims and resistance against homogenised national identification necessitate a rearrangement of salience and hierarchies in the selfconcept, both as an individual and as a group, and this calls for a transformation of the relation between culture, identity and society.

Studies on social dynamics of multicultural neighbourhoods are inconclusive as to the effect that diversity has on social contact, sense of belonging and civic participation. On one side, public spaces in multicultural neighbourhoods provide more opportunities for social interaction among residents that goes beyond ethnic ties. Diversity in mixed neighbourhoods helps to enrich social networks (Musterd and Andersen, 2006; Van der Laan Bouma-Doff, 2007). On the other side, this does not mean that people intrinsically dwell in multicultural encounters. Van Beckhoven and Van Kempen (2003) argue that "people like to live together with those who are like them" (in ethnicity or lifestyle) (see also Blokland and Van Eijk, 2010; De Vos, 2005). Preference for co-ethnic socialisation is not uncommon behaviour in public spaces. While this may not be grounded on prejudices, it has its effects on the social dynamics of a multicultural setting, such as resorting to public spaces for leisure and relaxation where members of one's ethnic group go. Peters and de Haan (2011) also observed that this selective behaviour prevails in highly multi-ethnic settings. Public spaces in multicultural neighbourhoods serve the function of allowing mundane encounters between individuals of 
different ethnic origin, but lack support for lasting social relations beyond brief encounters (Peters and de Haan, 2011). "Public and private lives are separate domains", conclude Peters and de Haan (2011: 184).

People that feel a sense of belonging to the neighbourhood are more likely to participate in community activities (Manzo and Perkins, 2006: 336). Participation in improving the community has also been related to the quality of established social ties between residents and the capital that can be mobilised through social networking (Butler and Robson, 2001). A stimulative physical environment supports greater use of public or "common" spaces (Kuo, Sallivan, Coley, and Branson, 1998: 823), while familiarity with the people and the immediate area generate a greater sense of community. In contrast, a fragmented social demographic may weaken the sense of belonging to the community and suppress civic engagement (Musick and Wilson, 2008).

Finally, studies on the personal attachment to neighbourhoods and a preference for co-ethnic public spaces underline the "political nature of people's connections to their community" (Manzo and Perkins, 2006: 339). Places are not the only mediator of individual presentation but also a communal self-presentation that conveys information about cultural and ethnic traits of users, social status and lifestyle. Researching the perception of white elderly folks on a local garden in Birmingham that accommodated symbols referencing to the Pakistani culture, Rishbeth (2001: 359) reports on dominant feelings of exclusion and unwelcome, as the "design was sending out a message that this project was for Pakistanis only". The identity of the place implied potential users and excluded others. Therefore, when symbols and cultural practices are spatialised in public space, they are used because of their ability to serve as territorial markers, to claim recognition of the existence and cultural perseverance, rather than as a tool that enhances the functionality of the place (Rishbeth, 2001: 359).

Public space is a salient category in creating place attachment, establishing social contacts and comprehending the wider political and social construct of belonging and citizenship. Poor planning or management practices and the quality of public spaces, both the physical characteristics and the social dynamics, remain crucial elements in creating viable multicultural encounters (Loukaitou-Sideris, 1995: 99). These are important notes for the potential of mixed neighbourhoods to serve as natural sites of positive intercultural contact. 


\section{THE RESEARCH CONTEXT: EXPERIMENTUM MACEDONICUM ${ }^{I}$}

This paper is focused on the city of Skopje, the capital of North Macedonia. It is a multi-ethnic city with a population of 506.926 inhabitants, according to the last official Census from 2002, where 66.75 per cent of the inhabitants are Macedonians, 20.49 per cent are Albanians, 4.63 per cent are Roma, 2.82 per cent are Serbs, 1.7 per cent is Turks and the rest is represented by smaller groups of Vlachs, Bosniaks, and others. The city is composed of ten municipalities. The Macedonian ethnic group represents a majority in seven municipalities, the Albanian ethnic group is a majority in two municipalities and the Roma in one municipality.

Multiculturalism in North Macedonia seems to be accepted as an inevitable outcome in an attempt to preserve the territorial coherence in a historical moment in 2001. The brief interethnic conflict interrupted the process of building a nation-state from within, as the nonmajority ethnic groups contested the single national identity. There is a consensus among the theoreticians in the country that while multiculturalism is a constitutionally supported value for the new social reality since 2001 , it seems neither normatively described, nor a clear and consistent policy (Dodovski, 2005; Sarkanjac, 2005, Janev, 2005). The project Skopje 2014 initiated in 2009 epitomises the idea of accommodation of one`s cultural memory and ethnic history in public spaces. This project revived the value of personal attachment to public spaces. As part of the project, in just a few years, 135 objects were accommodated in the urban core, producing a narrative of national identity based on mono-ethnic attributes of the Macedonian culture and its traditional conservative values. This ethnocratic ${ }^{2}$ use of space gave the ethnic groups their exclusive right to deal with the content (form, composition, symbols) accommodated in public spaces as a matter of internal importance excluding dialogue with Others, either ethnic or civic perceptions. This research is not about the spatial and social outcomes of Skopje 2014, although this project is inevitably a cross-cutting issue in any debate on how identity is symbolically linked to public spaces and how the process of urban planning can be used as an instrument of nationalistic rhetoric. The Skopje 2014 project revived the idea of the value of personal attachment to public space and how public spaces resonate in everyday discussion between the citizens. This is the focus of the present research.

\footnotetext{
${ }^{1}$ Term coined by Dodovski (2005).

${ }^{2}$ Yiftachel (1997: 507) describes ethnocracy as a regime where ethnicity overrules citizenship in the allocation of state resources and one dominant ethnic group is the driver of the political community and the policy discourse.
} 


\section{Methodology, Sampling and Field Work}

This research is based on mixed methods. The quantitative methodology used a two-stage probability sampling approach. In the first stage, two ethnically more homogenous (Kisela Voda and Saraj) and two mixed neighbourhoods (Chair and Butel) were selected. Selecting two mixed neighbourhoods offered an opportunity to analyse differences between localities with the opposite proportion between the major ethnic groups in the city, e.g. one neighbourhood where Macedonians compared to Albanians represents a numerical majority and the second neighbourhood where this ratio is the opposite. The second sampling stage involved identifying the eligible households and household members using Simple random sampling without replacement method. Stratification was done according to the type of settlement - urban and rural and the proportion of ethnic groups. The household survey, based on a structured questionnaire with 5 points Likert-type items achieved a net sample size of 403 respondents and a balanced representation between neighbourhoods.

To further understand individuals` responses, 30 interviews with residents of the selected neighbourhoods were conducted using an open-end questionnaire. The selection of interviewees was convenient. Gender and age were used as stratifying variables to ensure a diverse sample. None of the interviewees participated in both the interview and the survey. The fieldwork took place between October and December 2014.

\section{Survey Sample and Data Analysis}

In the sample, 52.6 per cent (212) were female and 47.4 per cent (191) were male. Concerning the ethnic background, 49.9 per cent of the respondents were Macedonians, 42.9 per cent were Albanians, and the rest are Serbs ( 1 per cent), Turks ( 1.5 per cent), Roma ( 0.7 per cent), Vlachs (0.7 per cent), Bosniak ( 3 per cent) and Bulgarian (0.2 per cent). Further, in the analysis, the "Others" category will be used to represent a composite measure of ethnicities other than Macedonians and Albanians. Concerning education, 3.5 per cent of the respondents had finished less than primary school, 34.7 per cent had primary education, 50.1 per cent had finished secondary school and 11.7 per cent had higher levels of education. Concerning the employment status, 28.5 per cent were employed and 16.4 per cent were unemployed persons, 23.3 per cent were housewives, 10.2 per cent were students and 18.1 per cent were retired persons. Fourteen persons ( 3.5 per cent) did not state their employment status. Further in the 
analysis, the categories "housewives", "students" and "retired persons" will be merged into "economically inactive".

Survey data processing encompassed quantitative analysis based on descriptive statistics (frequencies, crosstabs, central tendency summarised by median and variability using range and interquartile range ${ }^{3}$ ), Categorical principal components analysis and Principal component analysis, Kruskal-Wallis H Test and Mann-Whitney U Test. Statistical analysis was performed by SPSS. The obtained quantitative data was analysed with a margin of error of $+/-5$ per cent. The statistical difference is presented using p-value, for the level of .001 and .05.

The sample of interviewees consisted of 50 per cent of Macedonians, 44 per cent of Albanians, one Serbian (3 per cent) and one Turkish (3 per cent) respondent. Out of them, 53 per cent were female and 47 per cent were male respondents. In regards to their employment status, 57 per cent were employed, 10 per cent were unemployed and 33 per cent were economically inactive. The majority of the respondents had finished secondary education (50 per cent), 47 per cent had higher education and 3 per cent had finished primary school.

The analysis of the qualitative data involved two coding cycles. The first coding cycle utilised Structural coding, employing concepts determined in the theoretical framework, the research questions and the factor analysis. Further, in the second coding cycle, responses were deducted to themes using Pattern coding method.

\section{RESULTS}

Based on the literature and previous research, it was hypothesised that: The level of deliberative participation of citizens is expected to grow with the rising level of education and the employment status and is differing between ethnic groups in a numerical majority and minority status, and between the types of neighbourhoods.

The results indicate that most respondents have not participated in a local deliberative process where accommodation of diversity in the public space of the neighbourhood had been discussed $(\mathrm{Mdn}=1.5, \mathrm{IQR}=2.5)$. Majority respondents, 55 per cent of them, reported to had never been to a Local Council meeting and 53 per cent reported to have never been part of a working group

\footnotetext{
${ }^{33}$ Higher Median score and lower IQR on each item indicate the "likeliest: response or what the "average" respondent might think. Higher IQR means that data is more spread through the data points.
} 
in the neighbourhood discussing accommodation of diversity in public space. Around a quarter of the residents had participated in such activities ( 23 per cent had been at a Council meeting and 28 per cent had participated in working groups).

There was a statistically significant difference in the participation level among education groups $(\chi 2(2)=13.829, p=.001)$. Thus, people with a lower level of education are more likely to participate in deliberative activities on a local level than people with a higher level of education. Understanding the relationship between the employment status and the level of participation, Kruskal-Wallis $\mathrm{H}$ test showed a statistically significant difference in the level of participation among groups of different employment status $(\chi 2(4)=7.261, p=.027)$. There was a significant difference between the level of participation between employed and unemployed persons $(\mathrm{U}=$ 2824.500, $\mathrm{p}=.009$ ) with employed people being more likely than unemployed people to participate in deliberative activities on a local level. A difference between unemployed and economically inactive persons was also confirmed. The level of participation of economically inactive was statistically significantly higher than unemployed persons $(U=5794, p=.018)$, thus indicating that economically inactive were more likely than unemployed persons to participate in deliberation activities on a local level.

The results showed a statistically significant difference in the level of participation among ethnic groups $(\chi 2(2)=68.584, p<.001)$. Macedonians and Albanians showed a statistically significant different level of participation with Albanians showing higher likelihood to participate in deliberation activities than Macedonians. 78 per cent of Macedonians and 70 per cent of Others compared to 26 per cent of Albanians had never attended a meeting of the Local Council where issues of accommodation of diversity had been discussed. More so, 72 per cent of the Macedonians compared to 30 per cent of Albanians and 57 per cent of Others had never been part of a citizen working group where accommodation of diversity had been discussed.

Finally, the results showed that residents in the mixed and ethnic neighbourhood did not differ significantly in their level of participation $(U=18142, p=.407)$.

In order to understand the relationship between the social characteristics of the public spaces in the neighbourhoods and the prospect of facilitating communication and exchange between ethnic groups, the following was hypothesised: Citizens perceive public space as an essentialised ethnic space that serves the function of co-ethnic exchange and this is more so the case in ethnic than in mixed neighbourhoods.

According to the results, most respondents preferred co-ethnic socialisation in the public spaces of their neighbourhoods $(\mathrm{Mdn}=4, \mathrm{IQR}=2)$. The results $(\mathrm{U}=14138, \mathrm{p}<.001)$ showed a 
statistically significant difference in the level co-ethnic socialisation preference among residents of mixed and ethnic neighbourhoods. Despite expectations, residents in mixed neighbourhoods, more so than those in ethnic neighbourhoods, prefer co-ethnic socialisation in public spaces.

Even in general, citizens prefer co-ethnic socialisation in public spaces ( $M d n=4, I Q R=3)$. The majority of respondents preferred to socialise with people from their ethnic group in the public spaces in their neighbourhood (26.1 per cent strongly agree and 33 per cent agree). A small proportion opted for the opposite behaviour (13.5 per cent disagree and 11.4 per cent strongly disagreed). Yet, this preference was more strongly supported by those in mixed areas (26 per cent partly agreed and 39.5 per cent strongly agreed compared to 40.2 per cent who partly and 12.4 per cent who strongly agreed in ethnic neighbourhoods).

Similar outcomes are found in regards to the selection of places for socialisation $(\mathrm{Mdn}=4$, $\mathrm{IQR}=3$ ). The majority of respondents argued that while choosing public spaces to socialise and recreate, they opted for places where people from their ethnic group go (57.9 per cent) and a sizeable proportion disagreed with such a mode of selection of places (27.4 per cent disagreed and 13.4 per cent strongly disagree). Residents in ethnic and mixed neighbourhoods had different patterns of choosing public spaces $(U=16066.5, p=.004)$. Despite expectations, residents in mixed neighbourhoods more often than those in ethnic neighbourhoods opted for public spaces where people of their ethnic group go. The majority of residents of mixed neighbourhoods strongly agreed with such preference (45.1 per cent) compared to the ethnic neighbourhoods ( 9.8 per cent).

Citizens`opinions are less polarised concerning cross-cultural participation in events happening in the public space $(\mathrm{Mdn}=4, \mathrm{IQR}=2)$. The majority of respondents only participated in cultural events that celebrated their own ethnic culture (36.3 per cent strongly and 26.7 per cent partially agreed). Residents from the different types of neighbourhoods showed a statistically significant difference in the preference for participation in co-ethnic events $(U=11803, p<.001)$. In contrast to expectations, residents in mixed neighbourhoods more often than those in ethnic neighbourhoods showed a preference for co-ethnic events in public space. The majority of residents in mixed neighbourhoods only participated in co-ethnic events (52.9 per cent strongly and 18.8 per cent partly agreed) compared to the ethnic neighbourhoods (19 per cent strongly and 34.8 per cent partly agreed).

Macedonians, Albanians and Others share a similar pro-social attitude towards one's group $(\chi 2(2)=3.123, p=.210)$. Thus, ethnic co-socialisation is not practised by a specific ethnic group 
only. The majority of Macedonians tend to choose public spaces where their ethnic group go (27.5 per cent strongly and 37 per cent partly agreed), similar to the majority of Albanians (46.5 per cent strongly and 15.5 per cent partly agreed) and members of small non-majority groups (27.4 per cent strongly and 30.5 per cent partly agreed). Also, the majority of Macedonians choose to socialise with their ethnic group in public space (28.9 per cent strongly and 37.3 per cent partly agreed) as do the majority of Albanians (22.6 per cent strongly and 28 per cent partly agreed). Small non-majority ethnic groups, while a great proportion supported co-ethnic socialisation in public space, also tend to be more open to cross-cultural communication (48.2 per cent supported and 44.8 per cent rejected co-ethnic socialisation). Cross-cultural participation is also less common for ethnic groups. The majority of Macedonians only participated in co-ethnic cultural events (41.9 per cent strongly and 26.3 per cent partly agreed) as so do the majority of Albanians (30.7 per cent strongly and 27 per cent partly agreed) and non-majority ethnic groups (30.8 per cent strongly and 26.9 per cent partly agreed).

To understand the potential of public spaces in the neighbourhoods to facilitate closeness between ethnic groups, it was hypothesised that: Citizens perceive public space as a source of proximity between members of co-ethnic groups and this is more the case with residents living in ethnic than in mixed neighbourhoods.

Most respondents agreed that the public spaces in their neighbourhoods offered proximity between different ethnic groups $(M d n=4, I Q R=2)$. The $U$ test $(U=17732.5, p=.028)$ showed that there was a statistically significant difference in the perceived level of ethnic proximity among residents of mixed and ethnic neighbourhoods. Residents of mixed neighbourhoods more often than those in ethnic neighbourhoods value public space as a source of proximity between different ethnic groups.

Getting to know people from other ethnic groups in the public space is an opportunity that is differently experienced by residents of ethnic and mixed neighbourhoods. In line with expectations, residents of mixed neighbourhoods found it easier to meet people from other ethnic groups in public space than those in ethnic neighbourhoods ( $U=15956, p=.010)$.

Although residents showed less interest in visiting a cultural event celebrating the culture of Others, they agreed that public space should be used by every group to mark and celebrate their culture $(\mathrm{Mdn}=4, \mathrm{IQR}=2)$. The majority of them feel comfortable (27 per cent partially and 36 per cent strongly agreed in contrast to 8.1 per cent who partially agreed and 7.6 per cent who strongly felt discomfort) with ethnic groups organising cultural celebrations and festivals in the public space of their neighbourhood. Examination of the potential difference between the types 
of neighbourhoods showed that residents of mixed and ethnic neighbourhoods differ in the acceptance of Others`cultural celebrations in public space $(U=15797, p=.023)$, with those in mixed neighbourhoods showing greater levels of comfort with such practice compared to residents of ethnic neighbourhoods. Residents of mixed neighbourhoods more often expressed comfort with Others`cultural celebrations in public space (46.6 per cent) compared to those in ethnic neighbourhoods (25.3 per cent).

Opinions also differ in the importance of representing ethnic and cultural symbols in the public space in the neighbourhood $(\mathrm{Mdn}=3, \mathrm{IQR}=2)$. Apparent disparities exist in the importance of the representation of ethnic and cultural symbols in the public space. An almost equal proportion of people agreed and disagreed that public space should be a symbol of the ethnocultural identity of its users. 13.1 per cent strongly and 25.8 per cent partially agreed on the significance of ethnocultural coherence between public space and its users, in contrast to 19.3 per cent (both strongly and partially) that found this to be irrelevant. There was no significant difference between residents in ethnic and mixed neighbourhoods on the importance of the representation of ethnic and cultural symbols in public space $(\mathrm{U}=17684, \mathrm{p}=.555)$. A somewhat equal proportion of residents in both ethnic and mixed neighbourhoods supported the coherence between space and ethno-symbolism (37 per cent in ethnic and 40.7 per cent in mixed neighbourhoods supported).

Lastly, residents of mixed neighbourhoods differ from those of ethnic neighbourhoods in the level of acceptance of Others' languages being spoken in public space without threat or fear $(\mathrm{U}=15455.5, \mathrm{p}=.001)$. As expected, residents of mixed neighbourhoods showed greater admiration for Others` languages compared with residents of ethnic neighbourhoods. The former more often strongly supported language diversity in public space (64.8 per cent) compared to those in ethnic neighbourhoods ( 42.5 per cent) who partly agreed with this practice (22.3 per cent in ethnic compared to 9.7 per cent in mixed neighbourhoods).

Presence and indirect contact between ethnic groups is possible in public spaces in both ethnic and mixed neighbourhoods. Segregated ethnic spaces in the neighbourhood with a restricted use by some ethnic groups were not identified. Parks, football stadium, schoolyards, streets, shopping malls, markets, recreational areas and children's playgrounds were considered as public spaces where ethnic groups could easily meet. For some interviewees, such spaces were characterised by tolerance for difference and conviviality. Yet, others observe a tendency toward spatial segregation, between ethnic groups and age cohorts, especially of public space in mixed neighbourhoods. A 59-year old Albanian man from Chair observed interethnic 
dynamics in public spaces as: "I don`t use joint public spaces in my neighbourhood. To be honest, I think it is even dangerous to have two different ethnic groups at the same place without a strong police presence". They do not report the existence of "pure" ethnic spaces but spaces that inhabit separation and co-ethnic compartmentalisation. Interestingly enough, these places are places for socialisation such as coffee bars, parks, squares where people from different ethnic backgrounds communicated within confined ethnic boundaries.

If ethnic compartmentalisation is evident in public spaces, what is the role of the collective ethnic and cultural symbols acknowledged in these spaces? How do they trigger feelings of belonging or discomfort? The residents in the mixed neighbourhoods find themselves confused and relentless toward the dominant ethno-symbolism in public space regardless of whether they are part of the numerical majority or not. A 58-year old Albanian man from Butel noted: "I feel like a stranger, not even as a citizen of Macedonia, neither Albanian”. His co-resident, a 32year old Macedonian male stressed: "Uncomfortably confused, I even don't know how to answer this, I dislike that certain religious symbols dominate and are overstressed in the public space". The marginalisation of state symbols during official and ethnocultural celebrations in mixed neighbourhoods is particularly distressing for the Macedonians. This practice was perceived as a threat to the symbolic definition of the nation, moreover, as an attack to the possibility of conviviality among ethnic groups in a shared space. "During state holidays the Macedonian flag is not represented in Chair. I am troubled by this because regardless of who we are as an ethnic group, we are part of the same state", argued a 62-year Macedonian woman who is an old settler in Chair. Similarly, the Albanians expressed their frustration of the message sent by the urban city centre: "This is a message that Albanians should not feel comfortable in their city, that they should not cross the river Vardar and socialise in the Orthodox part of Skopje", argued a 59-year old Albanian woman from Chair. The smaller ethnic groups, such as Turks in mixed neighbourhoods, felt invisible and marginalised in the symbolic struggle between the Macedonians and the Albanians. "In the city centre and Chair, the cultures of the Macedonians and Albanians are accommodated in the public space. The Turkish culture that had dominated this city for centuries is invisible. I am troubled by that fact and find it important that part of that history (my history) is also represented in the public space", noted a 33 -year old Turkish woman from Chair.

The use of the languages of Others triggers discomfort in destabilising the boundaries between ethnic groups, and in particular, this was the case with the use of the Albanian language as the second official language. The lack of understanding of the languages of Others inflicted fear 
and discomfort, in particular among Macedonians. "I don't like signs in Albanian language or bi-lingual boards. They give me discomfort!", argued a 65-year old Macedonian man from Butel. Albanian residents opted for bi-lingual public spaces, yet, they were not discomforted with the idea of using the Macedonian language when needed.

If this is so, who is the "appropriate citizen" represented in public spaces?! Based on citizens' views, this research identified that the daily negotiation of ethnic difference and the production of public space in our neighbourhoods are influenced by an ethno-nationalistic accommodation of diversity. Cultural and ethnic histories, languages, flags and monuments accommodated in the public space represent the "ethos" of the dominant group living there. At the same time, public space has a function of informing outsiders of those who occupy the space. In ethnic neighbourhoods where one group dominate along with a smaller proportion of other ethnicities, the public space is mono-cultural and inhabit symbolic significance reflective of the dominant ethnocultural narrative. In mixed neighbourhoods, colliding ethnonational narratives occupy the space. Any insurgency in the symbolic representation is perceived as a threat. A resident in an ethnic Macedonian neighbourhood epitomised this fear: "If Albanians come to make some celebrations in my neighbourhood, it is like they came into my house!". The division of "Us" and "Them" is implicit in how people perceive the space. And boundaries between ethnic groups were perceived as stable and not altered by adventurous trespassing. Ethnic background framed the use of public space, so in that respect, the group members feel comfortable in freely moving in spaces which accommodate their ethnic symbols, even more so, where the "normality" of space is constructed through their worldview. Some citizens find it appealing that symbols representing their ethnicity, culture and religion are visible accommodated in the public space but others feel disoriented and frustrated within the struggle of symbolic representation. And the latter feeling is not only supported by groups in minority status but also among members of groups in the majority in mixed neighbourhoods, those who fail to identify with the restricted view on identity and imagined "sameness" within the ethnic groups. These differing attitudes demonstrate the complexity of the relationship between identity and public space.

Macedonians more often raise concerns with changes in the ethnic boundaries that derive from the different spatial dynamic between ethnic groups. The lack of knowledge of Albanian language among the Macedonians enhance feelings of threat and takes away potential to exoticise the content of Other`s culture as an object of curiosity and exploration. The intention of keeping firm borders between ethnic groups, as with the insistence on the public use of the 
Macedonian language and private use of other local languages sustains the mental division of "Us" and "Them". In such contexts, it could only be expected that ethnic groups would continue with compartmentalisation within their own ethnic spaces and live a parallel life.

The different ethnic groups hold a different perception of the power hierarchy within the multicultural society. Macedonians speak more often of identity, belonging and citizenship based on national expressions of public culture, heritage, language and national symbols. For them, the agency of citizenship derives from the state language and national flag, the struggle for independence, and as they are all associated with the Macedonian ethnic group, the source of citizenship is inevitably rooted within the Macedonian political community. Macedonians more often perceive Others as "add-on" cultures to the national (Macedonian) culture. In contrast, Albanians and other smaller ethnic group more often speak of the "citizen" as a cultural mosaic, having a specific ethnic belonging, language, history and heritage, but who is a part of the political community and, as such, is entitled to a fair distribution of public goods. For both, Macedonians and Albanians, the symbolic representation in public space derives from the right of the group for self-preservation. Yet, the Macedonians prefer accommodation of Otherness as assimilated and blended into a single public culture. In their private space, ethnic groups could exercise their specific ethnocultural practices, but in the public space congruence with the established, common public culture is argued as an obligation of loyal citizens. Albanians contest this conception of national citizenship, yet, fail at recognising that in the territory where they represent the majority, minority claims should also be acknowledged. The smaller ethnic groups feel in-between the symbolic wars between Macedonians and Albanians. Thus, the two numerically dominant ethnic groups collide in their exclusive ethnonational narrative of belonging. Both ethnicise the space, the former by a nation-building process, and the latter by ethnonational preservation practices. Thus, the patterns of constituting "the citizen" in the public space are shaped by the ethnocultural symbols of the major ethnic groups. While in some case they reinforce citizenship as understood by the dominant ethnic group, in only a few cases they are challenged by a new "multicultural" citizen. These are situations where culture, and in particular ethnic belonging is separated from national belonging and accommodated in public space through the local symbolic landscape using ethnographic elements of the ethnic groups, such as habits, customs, food and folklore. These images can reinforce the dialogue between local/urban and national identifications, allow differential and bottom-up approaches in dealing with the incoherencies between identity and belonging, but are rigid in a fragmented pluralistic context. 


\section{DISCUSSION}

\section{The Political Value of Public Space: deliberation, atomised citizenry and clientelism}

In multicultural societies, the plurality of values and needs of different interest groups, ethnonational, cultural and other, makes it more difficult the prospect of coming to the consent of public good. This research identified that arriving at a common-sense on the accommodation of diversity in public spaces is a difficult process. A low level of participation in local deliberation activities was confirmed among citizens in both mixed and ethnic neighbourhoods. This suggests that citizens in Skopje neither discuss, talk and debate on policy issues of common interest with their co-citizens, nor are they interested to debate issues with their elected representatives in the municipal bodies. The apparent lack of participation also sheds light on the willingness of the municipal administration to engage in more immediate democratic exercises.

While the current findings on the relationship between participation and employment, and majority-minority status complement the prior research knowledge, some of the other "traditional" effects of socioeconomic status on participation were not confirmed. Lower educational levels were motivational factors for deliberation engagement. The political culture of clientelism seems to trigger citizen engagement or that these social groups have been more easily mobilised on the deliberation of accommodation of diversity in a context of changing ethnic geographies of neighbourhoods. In recent years, the way diversity had been represented physically and symbolically, instigated discussions, protests and activism. Yet, it seems that mobilisation of the wider citizenry on deliberating this issue remains low. Even more so, no debate is taking place on how a multicultural city should be governed with a recognition of diversity.

\section{The Social Value of Public Spaces: proximity, acceptance and self-segregation of ethnic groups}

Establishing and sustaining multicultural contacts in a city of diversity is not a spontaneous or natural aspect of intergroup encounters. The present findings showed that residents of mixed neighbourhoods have a higher preference for co-ethnic socialisation compared to those living in ethnic neighbourhoods. Residents in mixed neighbourhoods more often than those in ethnic 
neighbourhoods opted for co-ethnic cultural events in co-ethnic public spaces demonstrating in-group favouritism. More diversity could have resulted in more inclination for interethnic contact and solidarity, as suggested by the contact theory. Instead in the multi-ethnic neighbourhoods in Skopje, self-segregation of ethnic groups is prevalent and it could be detrimental to a functional multi-ethnic society and a convivial multicultural city.

Citizens of Skopje hardly ever transgressed fixed ethnic borders and those that prefer co-ethnic socialisation rarely explored other cultures. Co-ethnic socialisation was not a preference of a specific ethnic group. Macedonians, Albanians and Others shared a similar pro-social attitude towards one's group. Residents in mixed neighbourhoods that preferred co-ethnic socialisation also tended to select public spaces with people from their ethnic group. In contrast, people in ethnic neighbourhoods showed greater curiosity and preparedness for intercultural ventures.

Proximity to other ethnic and racial groups is the initial step in counter-fighting the social segregation and public spaces in mixed neighbourhoods provided social closeness. Yet, this positive inter-ethnic attitude does not mean that people were prepared to step forward in cooperation with other ethnic groups. Feeling comfort with public events of other ethnic groups happening in shared spaces and greater acceptance of public use of Others' languages are contrasted with the lived practice of self-compartmentalisation in public spaces in mixed neighbourhoods. Living among Others results in "public familiarity" with diversity. Encountering diversity even when these contacts do not transform into durable social ties, impacts an attitude of "civility towards diversity". Yet, liking diversity is different from practising diversity, as argued by Blokland and Van Eijk (2010). But why do public spaces in Skopje fail to support intercultural contact? 


\section{Citizenship and Belonging in a Multicultural Context}

In the case of Skopje, the practices of accommodation of diversity in public space support expressions of citizenship that are limited to the nation-state and ethnic identification. Contact between ethnic groups is happening in the context of a notable ethnocratic transformation of public spaces. The numerical share had been used as a source of legitimacy for practices of accommodation of the cultural specificity in public spaces. The colliding ethnocratic accommodation of diversity in public space, especially in mixed neighbourhoods, generated a sense of symbolic threat and forged people to compartmentalise within their ethnic group.

Public spaces provided some positive experiences with diversity but did not generate acceptance and visual recognition of symbols of other ethnic histories and cultures. To the contrary, questioning a common-sense order of things and their alignment with national unity and belonging was not at ease. Conformity over language(s) used in public space generated disagreements between citizens. The use of languages of other ethnic groups was as a matter of the private sphere, in particular among the Macedonians. This clashing division parallels an aversion in seeing signs in public spaces written in the languages of ethnic minorities and is interpreted as a threat to the national unity, argued also by Coopmans, Lubbers and Meuleman (2015). For Macedonians, rejection of language normativity questioned the authority of the state (held by the national group) and the symbols that bonded people together. In contrast, Albanians were more supportive of language diversity, with the comfort of basic understanding of the language of the Others. So, are the Albanians more multiculturalist than the Macedonians remain to be answered by other research.

The question of diversity and plurality in multicultural societies is not only of ethnic and cultural identities that are confined to the private sphere of the individuals. The essentialist framework on citizenship, belonging, legitimacy and loyalty ignores the "deep material differences in social position, a division of labour, socialised capacities, normalised standards and ways of living" (Benhabib, 2007: 80). How then to reconcile recognition of the cultural autonomy of ethnic groups with civic values of citizenship? The starting position is to reshape ethnic identity and break the "natural" aspect of a group`s existence. Ethnic identity is relational, as argued by Taylor (1994), it is constructed through the social interaction of individuals, groups and institutions. Shifting the essentialist understanding of the role of cultural and ethnic markers/identifications in a group`s existence and sustenance to a more "interactive" quality of identity, including discussion on boundaries, transgression, internal diversity and acts that bind people together, should be an important lesson for the multicultural 
discourse in Macedonia. In such constellation, cities and urban identity may gain importance and struggle to develop active citizenship as a dimension of identification with space/place.

\section{CONCLUSION}

Diversity is a reality in Skopje and its neighbourhoods. Public spaces in Skopje have been devalued because:

- Citizens are fairly excluded from any deliberation on the planning process of public spaces in their immediate environment and the neighbourhood;

- The technical planning and social programming of public spaces in the neighbourhoods do not stimulate curiosity and interest in learning about Others, acceptance and practices of convivial living and fail to instigate civic consciousness and mobilisation for the common good;

- The narrative of public spaces tells a story of a nation being built that undermines the autochthon multicultural reality of our neighbourhoods and the contemporary urban needs of its residents such as de-categorisation from stereotypical perceptions of "Us" and "Them" and introduction of flexibility, contestation, transgression and insurgencies in the dialogue between ethnically-based expressions of culture and civic, (more) universalistic understandings of place, belonging and community;

- Public spaces are a reflection of a society that is deeply ethnically and socially divided, infused with fears of Others, a sense of collective threat and with lack of imaginaries of commonness such as social justice, equality and rule of law.

Looking at the intergroup contact that evolved in conflict, this research concludes that bringing people together in contact is not enough. Interethnic proximity with a tendency for co-ethnic socialisation should be understood in a dialectical relationship between diversity and space. It is here that both the beneficial and erosive effects of diversity over the neighbourhood emerge. And this is more than just an effect of poorly planned physical spaces. It is a reflection of the lack of social planning of spaces, differences in social status and a reflection of the divided society on many levels: linguistically, in education and cultural consumption.

In a socio-political context where the quality of interethnic relations is shaped by the symbolic "war" happening in public spaces, the discussion on socio-spatial integration cannot be separated from a debate on how to plan the public spaces that promote socio-spatial integration 
in everyday multiculturalism. What the contact theory undermines is the influence of the context of the contact. The changing ethnic demography of the neighbourhoods in Skopje was followed by other socio-cultural and visual transformations of the public spaces that may have intensified the mistrust between groups and reflected a deeper fear of redistribution of power, resources, of challenged cultural values, beliefs and worldviews.

A major challenge of urban planning in a multicultural context is the accommodation of politics of recognition that accepts cultural independence within an individualistic framework of equality, equity and respect for difference. The political implementation of this challenge in urban policy necessities new planning principles and an enabling environment. A major issue is how to empower citizens to shift "access and presence into influence" (Goetz and Gaventa, 2001: 9) and as argued by Yiftachel and Huxley (2000), become part of the power hierarchy in the planning paradigm. More so, it is a matter of urgency to start conceptualizing urban citizenship, one that is open, flexible and inclusive for the diversity of residents, their needs and identifications, and one that mediates between national loyalty and local belonging. 


\section{REFERENCES}

- Allport, G.W. (1979) The nature of prejudice. 25th edn. Reading: Addison Wesley Publishing Company.

- Benhabib, S. (2007) 'Crises of the Republic: Transformations of State Sovereignty and the Prospects of Democratic Citizenship', in Habekost, E. (ed.) Justice, Governance, Cosmopolitanism, and the Politics of Difference: Reconfigurations in a Transnational World; Distinguished W.E.B. Du Bois Lectures 2004/2005. Berlin: Humboldt University, pp. 45-78.

- Blokland, T. and van Eijk, G. (2009) 'Do people who like diversity practice diversity in neighbourhood life? Neighbourhood use and the social networks of "diversity-seekers" in a mixed neighbourhood in the Netherlands', Journal of Ethnic and Migration Studies, 36(2), pp. 313-332.

- Butler, T. and Robson, G. (2001) 'Social capital, Gentrification and neighbourhood change in London: A comparison of Three south London Neighbourhoods', Urban Studies, 38(12), pp. 2145 2162.

- Coopmans, M., Lubbers, M. and Meuleman, R. (2015) 'To whom do national days matter? A comparison of national belonging across generations and ethnic groups in the Netherlands', Ethnic and Racial Studies, 38(12), pp. 2037-2054.

- De Vos, E. (2005) 'Public parks in Ghent's city life: From expression to emancipation?', European Planning Studies, 13(7), pp. 1035-1061.

- Dixon, J. and Durrheim, K. (2000) 'Displacing place-identity: A discursive approach to locating self and other', British Journal of Social Psychology, 39(1), pp. 27-44.

- Dodovski, I. (2005) 'Experimentum macedonicum - tragajki po idninata na multiculturalizmot (Experimentum macedonicum - searching for the future of multiculturalism)', in Dodovski, I. (ed.) Multikulturalizmot vo Makedonija: model vo nastanuvanje (The multiculturalism in Macedonia: model-in-progress). Skopje: Fondacija Institut Otvoreno Opshtestvo, pp. ix-xv.

- Duyvendak, J.W. (2004) 'Neighbourhoods, cohesion and social safety', in van der Vijver, K. and Terpstra, J. (eds.) Urban safety: Problems, governance, and strategies. Enschede: IPIT, University of Twente, pp. 27-35.

- Goetz, A.M. and Gaventa, J. (2001) 'From Consultation to Influence: Bringing Citizen Voice and Client Focus into Service Delivery', IDS Working Paper, 138.

- Hewstone, M. (2003) 'Intergroup contact Panacea for prejudice?', The Psychologist, 16(7), pp. 352355.

- Hewstone, M. and Greenland, K. (2000) 'Intergroup conflict', International Journal of Psychology, 35(2), pp. 136-144.

- Janev, G. (2005) 'Avtohtoniot makedonski multikulturen model (Autochthon Macedonian multicultural model)', in Dodovski, I. (ed.) Multikulturalizmot vo Makedonija: model vo nastanuvanje (Multiculturalism in Macedonia: model in-progress). Skopje: Fondacija Institut Otvoreno Opshtestvo, pp. 97-110.

- Kuo, F.E., Sullivan, W.C., Coley, R.L. and Brunson, L. (1998) 'Fertile Ground for Community: InnerCity Neighborhood Common Spaces', American Journal of Community Psychology, 26(6), pp. 823851.

- Lofland, L.H. (1998) The public realm: Exploring the city's quintessential social territory. Hawthorne: Aldine de Gruyter. 
- Loukaitou-Sideris, A. (1995) 'Urban form and social context: Cultural differentiation in the uses of urban parks', Journal of Planning Education and Research, 14(2), pp. 89-102.

- Madanipour, A. (1996) Design of urban space: An inquiry into a socio-spatial process. New York: John Wiley \& Son.

- Manzo, L.C. and Perkins, D.D. (2006) 'Finding common ground: The importance of place attachment to community participation and planning', Journal of Planning Literature, 20(4), pp. 335-350.

- Messick, D.M. and Kramer, R.M. (2001) 'Trust as a Form of Shallow Morality', in Cook, K.S. (ed.) Trust in Society. New York: Russell Sage Foundation, pp. 89-118.

- Musick, M.A. and Wilson, J. (2008) Volunteers: A social profile. Bloomington: Indiana University Press.

- Musterd, S. and Andersson, R. (2006) 'Employment, social mobility and neighbourhood effects: The case of Sweden', International Journal of Urban and Regional Research, 30(1), pp. 120-140.

- Peters, K. and de Haan, H. (2011) 'Everyday spaces of inter-ethnic interaction: The meaning of urban public spaces in the Netherlands', Leisure/Loisir, 35(2), pp. 169-190.

- Putnam, R.D. (2007) 'E Pluribus Unum: Diversity and community in the Twenty-first century the 2006 Johan Skytte prize lecture', Scandinavian Political Studies, 30(2), pp. 137-174.

- Rishbeth, C. (2001) 'Ethnic minority groups and the design of public open space: An inclusive landscape?', Landscape Research, 26(4), pp. 351-366.

- Sarkanjac, B. (2005) 'Multikulturalizmot vo Makedonija (Multiculturalism in Macedonia)', in Dodovski, I. (ed.) Multikulturalizmot vo Makedonija: model vo nastanuvanje (Multiculturalism in Macedonia: model in-progress). Skopje: Fondacija Institut Otvoreno Opshtestvo, pp. 14-27.

- State Statistical Office of The Republic of Macedonia (2005) Popis na naselenieto, domakjinstvata $i$ stanovite vo Republika Makedonija, 2002 - Kniga XIII (Census of Population, Households and Dwellings in the Republic of Macedonia, 2002 - Book XVIII). Available at: http://www.stat.gov.mk/Publikacii/knigaXIII.pdf (Accessed: 13 May 2018).

- Taylor, C. (1994) 'The Politics of Recognition', in Gutmann, A. (ed.) Multiculturalism: Examining the politics of recognition. Princeton: Princeton University Press, pp. 25-74.

- Van Beckhoven, E. and van Kempen, R. (2003) 'Social effects of urban restructuring: A case study in Amsterdam and Utrecht, the Netherlands', Housing Studies, 18(6), pp. 853-875.

- Van Der Laan Bouma-Doff, W. (2007) 'Confined contact: Residential segregation and ethnic bridges in the Netherlands', Urban Studies, 44(5), pp. 997-1017.

- Yiftachel, O. and Huxley, M. (2000) 'Debating Dominance and Relevance: Notes on the 'Communicative Turn' in Planning Theory', International Journal of Urban and Regional Research, 24, pp. 907-913.

\section{Acknowledgement}

This paper is based on the doctoral research of the author and was presented at the AESOP Annual Congress 2018 "Making Space for Hope" 10-14 July 2018, Gothenburg, Sweden. However, the full paper is not part of any conference proceedings. 